I would like to try and take the training issue forward. The College is to be congratulated on its stance. However the balance between senior registrars and more junior trainees may need to change. It would be difficult for senior registrars to give up their hard won privileges, but surely the emphasis in training ought to be on the least experienced not most.

The new funding arrangements for training posts should allow some principles to be established about the division between service and training. In Sheffield, as roughly half of the funding for SHO/ registrars will come from Trent Postgraduate, at least half of their time will be allocated to training. For the moment, we will continue to regard senior registrars as "supernumerary".

I am hopeful that the new Dean of the College will introduce some new thinking on training in psychiatry. This is not a criticism of the current or past Deans, who I know have successfully countered arguments like those of the Maudsley consultants.

DunCaN B. DOUble

Sheffield Pastgraduate and

Continuing Psychiatric Education

Middlewood Hospital

Sheffield S6 1TP

\section{Crisis intervention}

Dear Sirs

I was interested to read Dr Parkes' articles on the crisis intervention service in Tower Hamlets. (Psychiatric Bulletin 1992, 16, 748-753).

Redbridge, about ten miles from Tower Hamlets, has had a similar small multidisciplinary crisis intervention service operating during office hours since 1984. This complements the traditional inpatient, out-patient and CPN services and offers brief individual psychotherapy and family therapy supplemented where appropriate with medication. Similarly, psychiatrists do not see all cases. However, unlike Tower Hamlets, most cases are seen in the crisis team's office and self referrals are accepted.

We retrospectively examined all 119 patients referred from a single catchment area in 1989. Twenty-two per cent failed to attend with the remaining $78 \%$ attending for an average of 3.2 sessions. Only $10 \%$ were self referral, most being referred from psychiatrists or their GPs. Similar to Parkes' findings, there was a larger proportion of younger women with those in the 20 to 35 age group making up $36 \%$ of all those referred. Eighteen per cent of men and $33 \%$ of women were receiving psychotrophic medication on referral.

We followed up the group, an average of three years later, in mid 1992. Only seven patients had renewed contact with the crisis team during this period and five had attended psychiatric out-patients; $27 \%$ were on psychotrophic medication, usually a benzodiazapine or an antidepressant, although surprisingly this showed minimal correlation to use of medication in 1989. Of those who remained with their GPs, $41 \%$ were in regular contact for mental health problems. However, most of these had had no contact with any other psychiatric service in the previous six months.

Separately, as part of audit, we found a high level of patient satisfaction with this service.

\section{Goodmayes Hospital}

RICHARD DUFFETT

$$
\text { Barley Lane, Ilford }
$$

Essex IG3 8XH

\section{Section 5(2)-following the rules?}

\section{DeAR SIRS}

We audited the use of the Mental Health Act section $5(2)$ and found that we were not very good at following the workings of the Act of the Code of Practice. Forty-one per cent of our episodes involved patients who had been on the ward less than 12 hours, which raised questions about our definition of an in-patient (Code paragraph 8.4). This was complicated by the fact that patients were assessed for admission on the acute wards and not in the A \& E department. Most applications (73\%) were made by a senior house officer but only $18 \%$ sought advice, which the Code says should be done wherever possible. Approved social workers were involved only if a recommendation for admission under the Act was made, which the Code considers not to be good practice. Twenty per cent were 'allowed to lapse' after the second assessment which is contrary to the Act and receives regular criticisms from the Commission.

Our social work colleagues are more keen than we are to follow the letter of the legislation. Perhaps our priorities are different, evidenced by their frequent reference to paragraph 1.1 of the Code, that failure to follow the Code could be referred to in evidence in legal proceedings. They are in favour of policies and guidelines, and some have even suggested a maximum of six hours for the second assessment to be completed. As psychiatrists, our clinical freedom is within the Act and Code and my concern is that if we do not follow them more closely, more restrictive and rigid interpretations will be imposed. This would really affect our clinical freedom. We see this too often in social services and nursing; new untoward incidents lead to new policies.

Most Section 5(2)s are done by very junior trainees ( $41 \%$ were made by SHOs in their first psychiatric posts). When I asked junior trainees in two hospitals 
whether they had received teaching of any kind on the use of the Section 5(2), the majority said they had not. Training is essential but usually lacking. It should be done as part of the induction programme, and should include discussions of its use in different clinical situations.

c/o Department of Psychiatry

DAVID LI

Arrowe Park Hospital

Upton, Birkenhead

Merseyside

\section{What happens after the 'Ashworth Inquiry? \\ DEAR SIRS}

It is now some eight months since the report of the Committee of Inquiry into complaints about Ashworth Hospital, a document which will, no doubt, eventually assume its position in the annals of forensic psychiatry. I am surprised that there has been no mention of it in the Psychiatric Bulletin. Having worked, albeit many years ago in a special hospital, I thought it might be of interest to comment.

The inquiry revealed what nearly everyone who has worked in a special hospital must know; that there is, and has been for decades, an unhealthy 'psychopathic' element in special hospital staff culture, prone to bully and victimise patients and staff who cross its path. This is not to say that there are not many well motivated professionals working within these hospitals or that reputable assessment and treatment processes are not practised.

The inquiry was initiated by the Government due to media pressure, occasioned by Channel 4's documentary 'Cutting Edge'. Following a legal struggle with the Prison Officer's Association, it was successful in penetrating the circle of silence and intimidation, within which patient abuse can flourish. However the mandate of the inquiry was to inquire and expose, not rectify. What happens next?

Undoubtedly the inquiry dealt a severe blow to the morale of professionals working within the special hospitals. Demolition, without reconstruction, is not necessarily helpful. With their long history of problems, are the special hospitals going to be able to recruit professionals of the right calibre to struggle with what may be a thankless task? I think there is reason for doubt. Should this be so, the future for the special hospitals after the Ashworth Inquiry may be bleak not hopeful. The opinion of colleagues would be of interest.

Yew Tree House

C. M. GreEN

Potter Heigham

Norfolk NR29 SSB

\section{'Psychiatric opinion audiotaped'}

\section{DEAR SIRS}

We would like to report on giving patients audiotaped recordings of their psychiatric opinions after first consultations. This form of communication has been found to be beneficial when used in surgical out-patient clinics for women being told about their breast cancers (Hogbin \& Fellowfield, British Journal of Hospital Medicine, April 1989, 330-333).

The study was carried out in North Herefordshire with a population of around 40,000 . All new outpatient referrals were considered for entry. The patients were divided into immediate and delayed groups. The immediate groups constituted patients who would at completion of their consultation take the audiotapes home with them. The delayed groups consisted of patients who would have the audiotape recording made but would take their audiotapes four weeks later. The psychiatrist was blind as to which group the patient was in. Towards the end of each consultation an audiotaped recording was made of the psychiatric opinion and of any questions the patient asked. This recording would eventually be the property of the patient.

The patients completed assessment questionnaires at four and eight week intervals. The first questionnaire was a self rating questionnaire and scored eight items. Four items related to recall of initial consultation, two to compliance and report of side effects and the last two to satisfaction about the information given. The second questionnaire, rated at eight week intervals, was also a self rating questionnaire. It had six questions relating to the use of audiotape.

In all, 22 patients entered the study, 12 in the immediate group and ten in the delayed group. There was no significant difference in either two groups in terms of the recall of diagnosis, aetiology, suggested treatment and explanation of side effects, compliance with medication, or incidence of side effects. No patient felt that the information given was inadequate. Over $90 \%$ of the patients rated the information given as good or very good; $88 \%$ had listened to the tape since the first consultation. Of those who had listened, $73 \%$ listened to the tape with another person, usually the husband or partner. Most patients ( $88 \%$ ) rated the recording as useful or very useful; $83 \%$ did not find the recording disturbing.

Our initial view that, because of the patients' anxiety at the first consultation, they may not remember what was being said to them about their illness did not hold. The results show that there is no value in routinely audio-taping initial psychiatric consultations to improve patients' understanding of their illness. This would underline the fact that good personal communication skills between doctors and 